\title{
Implementation and Monitoring of Different Sample Collection Methods in Feather Mite Researches in Some Passerine Species
}

\author{
Esra PER ${ }^{1, *}$, Metin AKTAŞ ${ }^{\dagger}$ \\ ${ }^{1}$ Gazi University, Faculty of Science, Department of Biology, Teknikokullar, Ankara, Turkey. \\ ORCID ID: Esra PER: https:// orcid.org/0000-0002-7764-1215
}

\begin{abstract}
Received: 23.07.2019
Accepted: 11.09 .2019

Published online: 20.12 .2019

Issue published: 20.12 .2019

Abstract: A large majority of the researches on bird mites in the world and in Turkey is based on alive/dead birds and museum specimens. Ringing stations allow doing host and parasite-based monitoring work without harming birds. In this study, it was aimed to monitor the changes of ten mite species carried by bird species belonging to Passeriformes order in Cernek Ringing Station, Samsun in different years according to different collection methods. During the spring and autumn bird migration periods between 2010 and 2013, the feather mites of some passerine species were investigated by applying different sampling methods. Mite samples were collected with three different collection methods (Pyrethrin use, feather collecting, and mite collecting with forceps) and identified. The most appropriate collection method based on species and habitat diversity of mites, ease of operation and duration, and ethics is collecting and investigating the mites with the forceps by using a stereomicroscope. The feather mite species of the genus Dolichodectes, Proctophyllodes, and Trouessartia were determined on tail and wing feathers while the feather mites of Analges and Strelkoviacarus genera were determined on the abdominal feathers. This research, which was conducted at a ringing station where bird migration was investigated, shows that future acarology research in Turkey needs to be planned with experts from different areas of interest through an interdisciplinary approach.
\end{abstract}

Keywords: Cernek Ringing Station, Turkey, Passeriformes, feather mite, stereomicroscope.

\section{Tüy Akarı Araştırmalarında Farklı Örnek Toplama Metotlarının Bazı Ötücü Kuş Türlerine Uygulanması ve İzlenmesi}

Öz: Dünya'da ve Türkiye'de kuş akarlarına yönelik araştırmaların büyük bir çoğunluğu canlı/ölü kuşlar ve müze örnekleri üzerinedir. Halkalama istasyonları kuşlara zarar vermeden konak ve parazit temelli izleme çalışmalarının yapılabilmesine imkân vermektedir. Bu araştırmada Samsun, Cernek Halkalama İstasyonunda Passeriformes takımına ait kuş türlerinin taşıdığı on akar türünün farklı toplama metotlarına göre farklı yıllardaki değişimlerinin izlenmesi amaçlanmıştır. Çalışmada 2010-2013 yılları arasında ilkbahar ve sonbahar göç döneminde farklı örnek toplama yöntemleri uygulanarak bazı ötücü kuş türlerinin tüy akarları araştırılmıştır. Üç farklı toplama yöntemi (Piretrin kullanımı, tüy toplama ve pens ile akar toplama) ile akar örnekleri toplanmış ve teşhis edilmiştir. Akarların tür ve habitat çeşitliliği, çalışma kolaylığı, süre ve etik açıdan en uygun toplama yöntemi; stereo mikroskop kullanılarak pens ile akarların toplanması ve araştırılmasıdır. Kuyruk ve kanat tüylerinde Dolichodectes, Proctophyllodes ve Trouessartia; karın tüylerinde ise Analges ve Strelkoviacarus cinslerine ait tüy akarı türleri tespit edilmiştir. Kuş göçlerinin araştırıldığı bir halkalama istasyonunda yapılıış olan bu araştırma, Türkiye'de gelecekte yapılması planlanan akaroloji araştırmalarının farklı ilgi alanlarından uzmanlar tarafından disiplinler arası bir yaklaşım ile planlanması gerektiğini göstermektedir.

Anahtar kelimeler: Cernek Halkalama İstasyonu, Türkiye, Passeriformes, tüy akarı, stereomikroskop.

\section{Giriş}

Dünya'nın farklı birçok bölgesinde kuş halkalama istasyonları bulunmaktadır. Kuş halkalama istasyonlarında yapılan çalışmalar, kuş göç yollarının ortaya çıkarılmasının yanı sıra göç sırasında yakalanan kuş türlerinin davranışları ve taşıdıkları parazitlerin izlenmesi ile parazit konak ilişkisinin irdelenmesine de imkan vererek taksonomik ve ekolojik açıdan bilime önemli katkılar sağlamaktadır. Kuş halkalama çalışmaları, kuş ektoparazitlerinin araştırılması açısından yeni bir yol açmıştır. Bu istasyonlarda parazit canlının kuşa olan etkisi, kuşun davranışları ve reaksiyonları izlenebilmektedir (Peters, 1933).

Geçmiş yıllarda Dünya'da ektoparazitler ile ilgili araştırmalar ölü kuşlar üzerinden yapılırken günümüzde kuş halkalama çalışmaları ile kuşa zarar vermeden canlı birey üzerinden ektoparazitleri toplanabilmektedir (Watson \& Amerson., 1967). Dünya' da ve Türkiye'de kuş akarlarına yönelik araştırmaların büyük bir çoğunluğu sistematik temelli olup, bu araştırmalarda rastlantısal olarak yakalanmış olan kuş bireyleri ile müze örnekleri kullanılmakta (Gaud \& Atyeo, 1996) ya da sis ağları kullanularak (Mironov \& Fain, 2003; Mironov \& Galloway, 2002; Gürler, Mironov, \& Erciyas-Yavuz, 2013) canlı kuş bireyleri üzerinden araştırmalar yapılmaktadır.

Türkiye'de Cernek Kuş Halkalama İstasyonu'nda kuş göçü izleme araştırmaları kapsamında 2000 yılından itibaren ilkbahar ve sonbahar kuş göçünde göç eden ötücü kuşlar yakalanarak halkalanmaktadır (Doğa Koruma ve Milli Parklar Genel Müdürlüğü, 2018). Tüy akarlarının birlikte yaşam birliği oluşturduğu ötücü kuşlardan Passeriformes takımına ait bazı kuş türleri Türkiye'de ilkbahar ve sonbahar göçünde Kızılırmak Deltası'nda yüksek birey sayıları ile temsil edilmektedir. Bu türlerin bazı bireyleri her yıl göç döneminde bu alanı kullanmakta ve bunların göçleri geniş bir zaman diliminde gerçekleşmektedir. 
Kuşların üzerindeki tüy akarları, sınırlı bir bölgede hareket ederek farklı mikro habitatları işgal etmektedir (Dubinin, 1951; Perez \& Atyeo, 1984). Tüy akarlarının işgal ettiği dört ana mikro habitat; yumuşak hav tüyleri, kontur tüylerinin kanat yüzeyleri, uçma ve kuyruk tüylerinin içi ile cilt yüzeyidir (Gaud \& Atyeo, 1996). Tüy akarları genellikle kuyruk ve uçma teleklerinde bulunmaktadır (Clayton \& Walther, 1997; Dabert \& Mironov, 1999). Türkiye' de kuşların tüy akarlarına yönelik olarak farklı metotlar uygulanarak uzun dönemli bir izleme çalışması yapılması özellikle akar-konak özelleşmesi, habitat tercihi ve zamansal değişimin ifade edilmesi açısından önemlidir.

Bu araştırmada Kızılırmak Deltası (Samsun) Cernek Halkalama İstasyonunda Passeriformes takımına ait bazı kuş türlerinin taşıdığı on tüy akarı türünün farklı toplama metotlarına göre farklı yıllardaki değişimlerinin izlenmesi amaçlanmıştır.

\section{Materyal ve Metot}

$\mathrm{Bu}$ araştırma 2010-2013 yılları arasında ilkbahar ve sonbahar kuş göç döneminde Samsun ili, Ondokuzmayıs - Bafra ve Alaçam ilçe sınırlarındaki Kızılırmak Deltası'nda bulunan (Şekil 1) Yaban Hayatı Geliştirme Sahası sınırları içinde, Cernek Kuş Halkalama İstasyonunda gerçekleştirilmiştir.

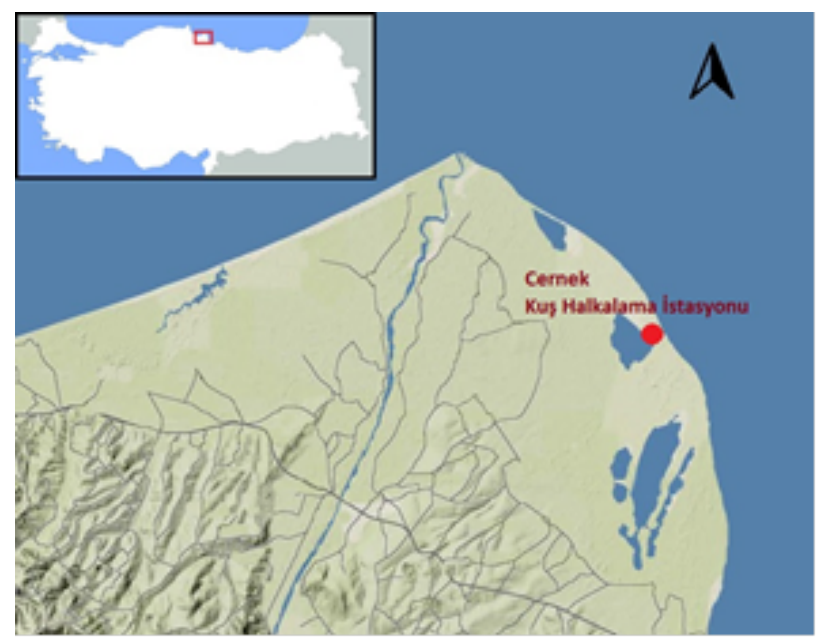

Şekil 1. Kızılırmak Deltası, Cernek Kuş Halkalama İstasyonu.

Halkalama İstasyonu'nda ilkbahar ve sonbahar kuş göç döneminde halkalanan Passeriformes takımına ait on tür araştırma materyali olarak kullanılmıştır. Bu türler dünyanın farklı bölgelerinden geldikleri için göçe başlama tarihleri de farklılık göstermektedir. Alanda gerçekleştirilen pilot çalışmalarda kuşlarda ektoparazit incelemeleri yapılmış olup en fazla tüy akarı Acrocephalidae, Phylloscopidae, Scotocercidae ve Sylviidae familyası türlerinde görülmüştür. Bu bilgiler doğrultusunda, 10 ötücü kuş türünün tüy akarları toplanmıştır. Bu türler Acrocephalidae familyasından; Acrocephalus arundinaceus (Büyük kamışçın), Acrocephalus scirpaceus (Sazbülbülü), Scotocercidae familyasından; Cettia cetti (Kamış bülbülü), Phylloscopidae familyasından; Phylloscopus collybita (Çıvgın), Phylloscopus trochilus (Söğüt bülbülü), Sylviidae familyasından; Sylvia atricapilla (Karabaşlı ötleğen), Sylvia borin (Boz ötleğen) Sylvia communis (Akgerdanlı ötleğen), Sylvia curruca (Küçük akgerdanlı ötleğen) ve Sylvia melanocephala (Maskeli ötleğen)'dır.
Arazi çalışmaları için Tarım ve Orman Bakanlığı'ndan izin alınmıştır. Uzman halkacıların gözetiminde etik kurallar doğrultusunda kuşlara zarar vermeden 3 farklı yöntem kullanılarak tüylerinde yaşayan akarları toplamaya yönelik bir çalışma yapılmıştır.

Kızılırmak Deltası Yaban Hayatı Koruma Sahası, Cernek Kuş Halkalama İstasyonu'nda kuşlar standart sis ağları kullanılarak yakalanmıştır (Şekil 2A). Her bir birey havalandırma deliği bulunan ayrı ayrı kese kâğıtlarında taşınarak bireyler arası kontaminasyon engellenmeye çalışılmıştır (Watson \& Amerson, 1967) (Şekil 2B).

Lisanslı kuş halkacıları tarafından halkalanan her bir birey (Şekil 3A) tüy akarları açısından incelenmiştir (Şekil 3B). Ektoparazit incelemesinden geçen her bir kuş türüne bir kod numarası verilmiş ve kese kâğıtları etiketlenmiştir. Her bir kuş bireyi strese girmeden kısa sürede akar örnekleri toplanmıştır.

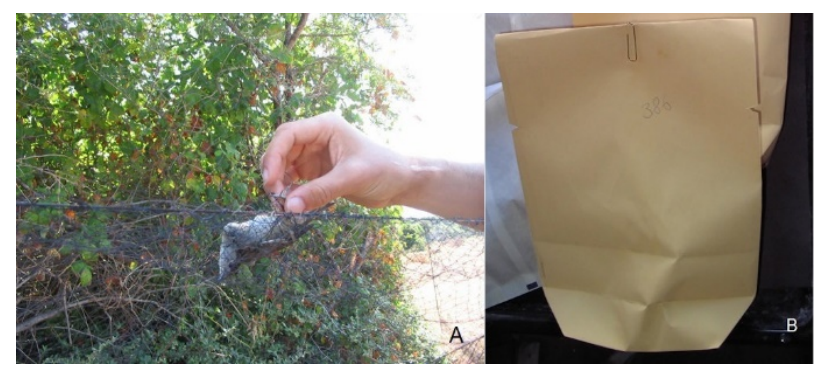

Şekil 2. A-Sis ağlarına yakalanmış bir birey B-Bireylerin taşındığı kese kağıdı.

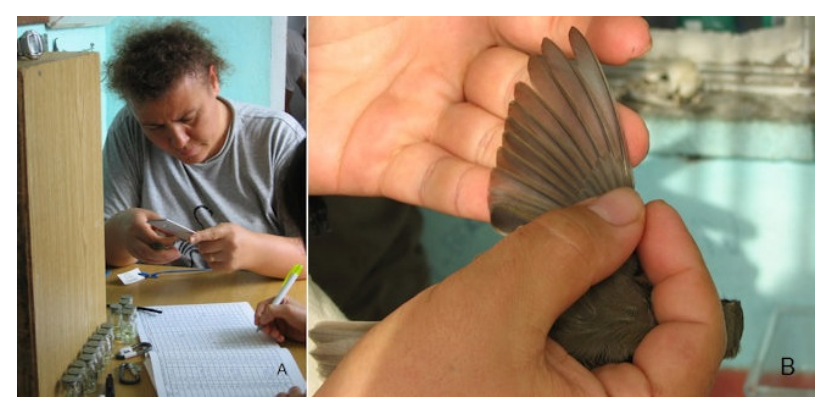

Şekil 3. A-Halkacı tarafından ölçümleri alınan, B- Telekleri kontrol edilen bir birey.

Akar örneklerini toplamak için ilk metot olarak 2010 yılında piretrin kullanılmıştır (Watson \& Amerson, 1967; Clayton \& Walther, 1997). Ektoparazitleri toplamak için her bir kuş bireyi bitkisel kökenli piretroidli bir pestisit tozu ile ilaçlanmıştır. Kullanılan piretrin, bazı kasımpatı bitkilerinde doğal olarak bulunan bir pestisittir (Şekil 4A). Bu işlem sırasında siyah renkli karton kullanılarak pestisit tanecikleri ve ektoparazitler toplanmıştır. İlaçlanan birey 2 dk. süresince başı dışarıda kalacak şekilde kese kağıdı içinde tutulmuştur. $\mathrm{Bu}$ işlemin ardından hayvanın başı, kulağı, anüsü, kanat altı ve göğsü üzerinde yeniden bir inceleme yapılmıştır. Ektoparazitler yönünden incelenen kuş bireyleri tekrar doğaya salınmıştır. Kese kâğıdı ve siyah karton üzerine dökülen parazitler \%70'lik alkol solüsyonu içeren tüplere alınmıştır (Watson \& Amerson, 1967) (Şekil 4B).

İkinci bir metot olarak 2011 y1lında her bir birey üzerinde gözleme dayalı bir inceleme yapılmıştır. Akar taşıdığı belirlenen kuşların karın tüylerinden, kanat teleklerindeki sekonder-tersiyer tüylerden ya da kuyruk teleğinden bir adet tüy alınmıştır (Clayton \& Walther, 
1997). Her bir bireye ait tüy ayrı ayrı tüplere alınmış, kod numarası verilmiş ve etiketlenmiştir (Şekil 5A, B, C, D).

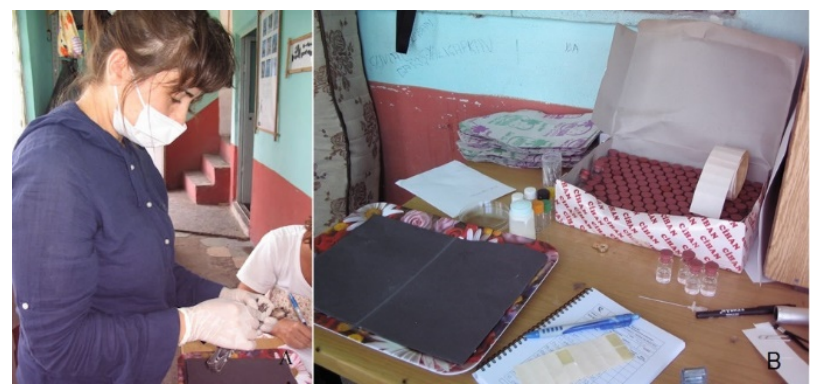

Şekil 4. A-Piretroidli bir pestisit tozu ile ilaçlanan bir birey, Bkullanilan malzemeler.

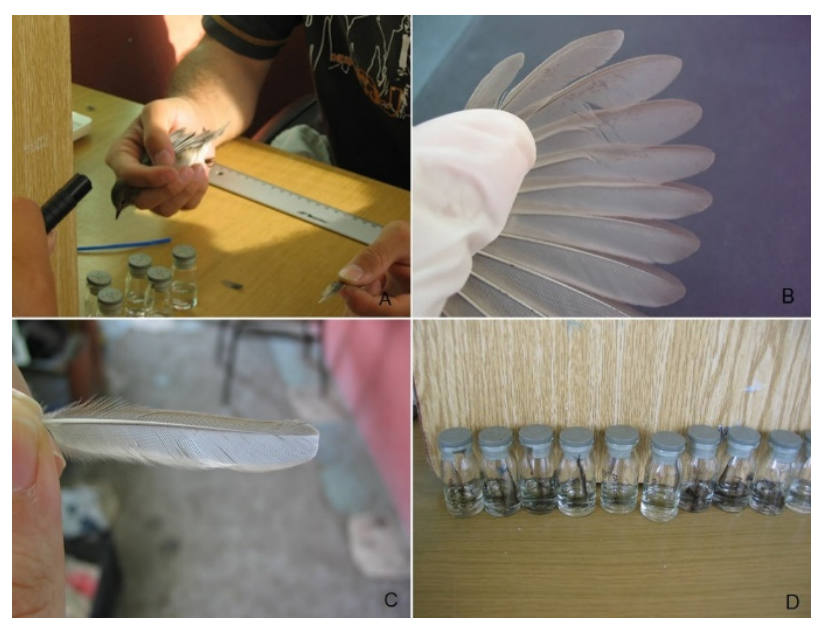

Şekil 5. A-Kuyruk teleklerinden tüy alınması, B- Uçma telekleri, C-Sekonder ve tersiyerden tüylerin toplanması, D-Tüylerin tüplere alınması.

Akar örneklerinin toplanmasinda 2012-2013 yıllarında Olympus marka stereo mikroskop kullanılarak üçüncü bir metot uygulanmıştır (Şekil 6A). Tüy akarları doğrudan kuşun üzerinden pens ile alınmıştır (Watson \& Amerson, 1967; Clayton \& Walther, 1997) (Şekil 6B).

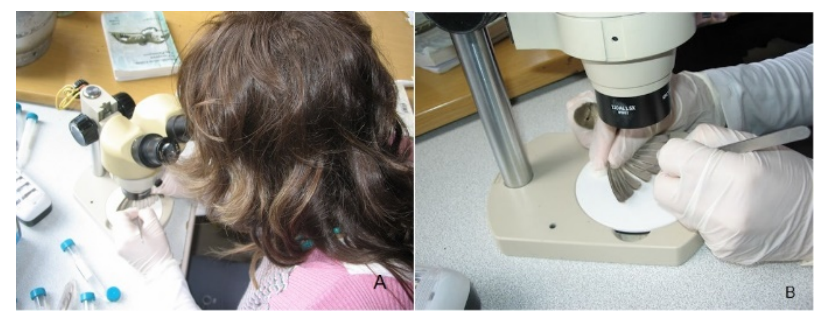

Şekil 6. A-Stereo mikroskop kullanılması B Tüy akarlarının pens ile toplanmasi.

Strese giren ve göçte yağ skoru yüksek olan kuşlardan örnek alınmamıştır. Farklı yöntemler ile toplanmış olan bütün örnekler \%70'lik alkol solüsyonu içeren numaralandırılmış tüplere alınmıştır. Tüplerin üzerine konak kuş türünün tür adı, halka numarası, tarih ve lokasyon bilgileri yazılarak arazi formuna kayıt edilmiştir.

Araziden getirilen her bir numune Gazi Üniversitesi Metin Aktaş Zooloji Müzesi'nde öncelikle stereo mikroskop altında incelenmiştir. İncelenen numunedeki akar bireyleri ince uçlu bir pens yardımı ile lamın üzerine yerleştirilmiştir. Kalıcı preparat yapabilmek için Hoyer
Eriyiği kullanılmıştır. Örneğin üzerine lamel kapatılarak kalıcı preparat haline getirme işlemi tamamlanmıştır. Örneklerin teşhisi Olymphus (CX21) 1şık mikroskobu ile gerçekleştirilmiştir. Tüy akarlarını teşhis etmek için çeşitli kitap ve makalelerden (Atyeo \& Braasch, 1966; Park \& Atyeo, 1971; Santana, 1976; Gaud \& Atyeo, 1996; Dabert \& Mironov, 1999; Proctor \& Owens, 2000; Proctor, 2003; O'Connor, 2009) yararlanılmıştır. Passeriformes takımından bazı ötücü kuş türlerinde tespit edilmiş olan akar türleri; Analges spiniger Giebel, 1871 Strelkoviacarus quadratus (Haller, 1882); Dolichodectes edwardsi (Trouessart, 1885); Proctophyllodes cetti Badek, Mironov, \& Dabert, 2008; Proctophyllodes clavatus Fritsch, 1961; Proctophyllodes doleophyes Gaud, 1957; Proctophyllodes sylvia Gaud, 1957; Trouessartia bifurcata (Trouessart) 1884; Trouessartia inexpectata Gaud, 1957; ve Trouessartia trouessarti Oudemans, 1904'tür. Tüy akarlarının Syviidae türlerindeki toplam enfastasyon oranı \%62.6 olup bu oran, türler arasında \%19.4-94.8 arasında değişiklik göstermektedir. Birey sayısı olarak en fazla inceleme, çalışılan alanda yüksek popülasyonlar ile temsil edilen Sylvia borin ve Sylvia atricapilla türleri üzerine yapılmıştır. Birey sayısı olarak en az inceleme Phylloscopus trochilus ve Acrocephalus arundinaceus türleri üzerinde yapılmıştır (Tablo 1) (Per \& Aktaş, 2018).

Tablo 1. İncelenen kuş türleri ve tüy akarı enfestasyon oranları.

\begin{tabular}{lccc}
\hline Kuş Türü & $\begin{array}{c}\text { Incelenen } \\
\text { Birey } \\
\text { Sayıs }\end{array}$ & $\begin{array}{c}\text { Akar Tespit } \\
\text { Edilen Birey } \\
\text { Sayısı }\end{array}$ & $\begin{array}{c}\text { Enfestasyon } \\
\text { Oran1 \% }\end{array}$ \\
\hline Acrocephalus arundinaceus & 7 & 5 & 71.4 \\
Acrocephalus scirpaceus & 16 & 4 & 25 \\
Cettia cetti & 87 & 52 & 56.5 \\
Phylloscopus collybita & 67 & 23 & 34.3 \\
Phylloscopus trochilus & 6 & 2 & 33.3 \\
Sylvia atricapilla & 156 & 148 & 94.8 \\
Sylvia borin & 153 & 114 & 74.5 \\
Sylvia communis & 33 & 9 & 27.3 \\
Sylvia curruca & 31 & 6 & 19.4 \\
Sylvia melanocephala & 30 & 7 & 23.3 \\
Toplam & $\mathbf{5 9 1}$ & $\mathbf{3 7 0}$ & $\mathbf{6 2 . 6}$ \\
\hline
\end{tabular}

\section{Bulgular}

Bu araştırmada 2010-2013 yılları arasında Acrocephalidae, Phylloscopidae, Scotocercidae ve Sylviidae familyasına ait 10 kuş türünden toplam 591 birey üzerinden akar örnekleri toplanmıştır. Acrocephalidae, Phylloscopidae, Scotocercidae ve Sylviidae familyasına ait kuş bireylerinin sayısı her yıl ilkbahar göç döneminde düşük, sonbahar göç döneminde yüksek olmuştur. İlkbahar mevsiminde ortalama 45, Sonbahar mevsiminde 152 birey incelenmiştir (Tablo 2). Kuş göçüne bağlı olarak İlkbahar'a oranla Sonbahar döneminde daha düzenli ve daha fazla veri sağlanmıştır.

Arazi çalışmalarında; 2010 y1lında piretrin, 2011 yılında tüy toplama, 2012-2013 yıllarında pens ile akarların tek tek toplanması şeklinde farklı toplama yöntemleri kullanılmış olup bir dönemde en az 7 en çok 10 akar türü tespit edilmiştir. Her ilkbahar aynı sayıda (7) akar türü tespit edilmiştir. Sonbaharda ise piretrin kullanılarak 10 tür, tüy toplayarak 9 tür ve pens ile akar toplayarak 10 tür tespit edilmiştir (Tablo 3). Bazı ötücü kuş türlerinde tespit edilmiş olan farklı tüy akarı türlerinin yıllara ve mevsimlere göre değişimi karşılaştırılmış olup 2012 yılı sonbahar mevsiminde araştırılmış olan bütün akar türleri 
(10) aynı göç döneminde tespit edilmiştir. Kuyruk ve uçma teleklerinde Dolichodectes, Proctophyllodes ve Trouessartia; karın tüylerinde Analges ve Strelkoviacarus cinsine ait tüy akarlarının yaşadığ Uygulanmış olan farklı tüy akarı toplama yöntemleri şu ölçütler ile karşılaştırılmıştır; biyoçeşitlilik, mikrohabitat tespiti, çalışma kolaylığı, süre ve etik. Tüy toplama biyoçeşitlilik açısından sınırlı kalmıştır. Piretrin kullanımı zaman alıc1, zor, kuşu strese sokan ve mikrohabitat tespitine izin vermeyen bir yöntem olmuştur. Stereo mikroskop kullanımı ise bu ölçütlere göre en uygulanabilir metot olmuştur (Tablo 5).

Tablo 2. On ötücü kuş türünde yapılan akar incelemesinin yıllara göre ve mevsimlere göre dağılımı.

\begin{tabular}{lllll}
\hline Y1l & Yöntem & İlkbahar & Sonbahar \\
\hline 2010 & Piretrin & - & 135 & Toplam \\
2011 & Tüy toplama & 77 & 143 & 135 \\
2012 & Stereo mikroskop & 33 & 178 & 220 \\
2013 & Stereo mikroskop & 25 & - & 211 \\
Toplam & - & 135 & 456 & 25 \\
Ortalama & - & 45 & 152 & - \\
\hline
\end{tabular}

Tablo 3. On ötücü kuş türünde tespit edilmiş olan toplam tüy akarı sayısının yıllara ve mevsimlere göre değişimi.

\begin{tabular}{|c|c|c|c|c|c|c|}
\hline & 2010 & & & & & 2013 \\
\hline & Sonbahar & İlkbahar & Sonbahar & İlkbahar & Sonbahar & İlkbahar \\
\hline $\begin{array}{l}\text { Toplam akar tür sayısı } \\
\text { Toplandığı bölge }\end{array}$ & $\begin{array}{c}10 \\
\text { Bütün vücut }\end{array}$ & $\begin{array}{c}7 \\
\text { Kuyruk, kanat, karın }\end{array}$ & $\begin{array}{c}9 \\
\text { Kuyruk, kanat, karın }\end{array}$ & $\begin{array}{c}7 \\
\text { Bütün vücut }\end{array}$ & $\begin{array}{c}10 \\
\text { Bütün vücut }\end{array}$ & $\begin{array}{c}7 \\
\text { Bütün vücut }\end{array}$ \\
\hline
\end{tabular}

Tablo 4. On ötücü kuş türünde tespit edilmiş olan farklı tüy akarı türlerinin yıllara ve mevsimlere göre değişimi.

\begin{tabular}{|c|c|c|c|c|c|c|c|}
\hline \multirow{2}{*}{ Akar türü } & \multirow{2}{*}{ Mikrohabitat } & \multirow{2}{*}{\begin{tabular}{|c|}
2010 \\
Sonbahar
\end{tabular}} & \multicolumn{2}{|c|}{2011} & \multicolumn{2}{|c|}{2012} & \multirow{2}{*}{$\begin{array}{c}2013 \\
\text { İlkbahar }\end{array}$} \\
\hline & & & İlkbahar & Sonbahar & İlkbahar & Sonbahar & \\
\hline Analges spiniger & Vücut (karın) & + & + & + & - & + & - \\
\hline Strelkoviacarus quadratus & Vücut (karın) & + & - & + & - & + & - \\
\hline Dolichodectes edwardsi & Kanat, kuyruk & + & + & + & + & + & + \\
\hline Proctophyllodes cetti & Kanat, kuyruk & + & + & + & + & + & + \\
\hline Proctophyllodes clavatus & Kanat, kuyruk & + & + & + & + & + & + \\
\hline Proctophyllodes doleophyes & Kanat, kuyruk & + & + & + & - & + & + \\
\hline Proctophyllodes sylvia & Kanat, kuyruk & + & + & + & + & + & + \\
\hline Trouessartia bifurcata & Kanat, kuyruk & - & - & + & + & + & - \\
\hline Trouessartia inexpectata & Kanat, kuyruk & + & + & - & + & + & + \\
\hline Trouessartia trouessarti & Kanat, kuyruk & + & - & + & + & + & + \\
\hline
\end{tabular}

Tablo 5. Uygulanmış olan farklı tüy akarı toplama yöntemlerinin karşılaştırılması.

\begin{tabular}{lccc}
\hline Ölçüt & Piretrin & Tüy toplama & Stereo mikroskop \\
\hline Tür çeşitliliği & + & - & + \\
Mikrohabitat tespiti & - & - & + \\
Kolaylık & - & + & $-/+$ \\
Süre & - & + & $-/+$ \\
Etik & - & + & + \\
\hline
\end{tabular}

Acrocephalidae, Phylloscopidae, Scotocercidae ve Sylviidae familyasına ait kuş türlerinde; Analges, Dolichodectes, Proctophyllodes, Strelkoviacarus ve Trouessartia cinslerine ait toplam 10 akar türü tespit edilmiştir. Bu araştırmada uygulanmış olan tüy toplama ve pens ile inceleme metotlarında; kuyruk ve uçma teleklerinde Proctophyllodes, Dolichodectes ve Trouessartia türlerinden, karın tüylerinde Analges ve Strelkoviacarus türlerinden tüy akarlarının yaşadığ $\breve{1}_{1}$ tespit edilmiştir. Piretrin kullanılmış olan bireylerin akarları, pestisitin etkisi ile kuşun vücudunu bir anda terk ettiği için bu akarlarm kuşun vücudunun hangi bölgesinde yaşadığı tespit edilememiştir. Passeriformes bireyleri üzerinde çıplak gözle doğrudan yapılan incelemelerde tüy akarı enfestasyonu tespit edilen bireyler üzerinde inceleme yapılmıştır. Bu bireylerde özellikle kuyruk ve kanat bölgesinde akar enfastasyonu daha yüksektir. Bunun nedeni kanat ve kuyrukta tespit edilmiş olan Trouessartia ve Proctophyllodes türlerine ait akar bireyleridir. Bu akar türlerinin, yumurtalarını tür şaftına (rachis) sırayla bıraktığı tespit edilmiştir (Şekil 7).

Tür teşhisi yapılırken birçok preparatta akarların besin içerikleri de görüntülenmiştir (Şekil 8). Bazı preparatlarda besin içeriklerinin yoğun olması tür teşhisini zorlaştırmıştır.

Arazi çalışmalarında yapılan ektoparazitolojik incelemelerde Acrocephalidae, Phylloscopidae, Scotocercidae ve Sylviidae familyasına ait türlerde sadece akar türleri tespit edilmiştir, diğer ektoparazitlerden bit, pire, sinek vb. canlılara rastlanmamıştır.

\section{Tartışma}

Türkiye'de tüy akarı taksonomisi çok yeni bir araştırma alanı olup, var olan araştırmalar genellikle kısa dönemli çalışmalardan oluşmaktadır (Aksın, 2007; 2010; 2011; Aksın \& Erdoğmuş, 2005; Gürler et al., 2013). Bu araştırma ile 2010-2013 yılları arasında ilkbahar ve sonbahar kuş göç döneminde yüksek birey sayıları ile temsil edilmekte olan Acrocephalidae, Phylloscopidae, Scotocercidae ve Sylviidae familyasına ait kuş türlerinin taşıdığı akar türleri farklı metotlar kullanılarak (pestisit yardımıyla, tüy toplayarak ve pens ile akar toplayarak) toplanmış ve dönemsel değişimler yıllara göre izlenmiştir.

Araştırmada 2010 yılında bitkisel kökenli bir pestisit olan Piretrin kullanılmıştır. Piretrin, akar dışındaki bit ve 
sinek gibi diğer ektoparazitleri toplamak için daha elverişlidir. Kuş bireylerinin üzerindeki akarları piretrin ile uzaklaştırmak en zahmetli, en uzun süreli, en stresli ve en tercih edilmemesi gereken yöntem olup bu yöntemin uygulandığı bazı kuş bireyleri üzerinde bir süre uçamama davranışı görülmüştür. Akarlar diğer ektoparazitlere göre çok daha yavaş hareketli ve belli bir vücut bölgesine özelleşmiş olduğu için pestisit kullanmadan da toplanabilmektedir. Bu nedenle 2011 yılından itibaren arazi çalışmalarında doğaya zarar vermemek için pestisit kullanılmamıştır. Piretrin kullanımı yerine her bir birey üzerinde gözleme dayalı bir inceleme yapılarak sekonder ve tersiyer ile karın ve kuyruk tüyünden biri koparılmıştır. Göçmen kuşlardan sekonder ya da tersiyerden bir adet tüy kopartıldığında sadece koparılan tüyde yaşayan akarlar tespit edilebilmektedir. Etik olarak göçmen kuşların primer tüylerinden tüy koparmak sakıncalı olduğu için bu bölgeden tüy toplama yapılmamıştır.

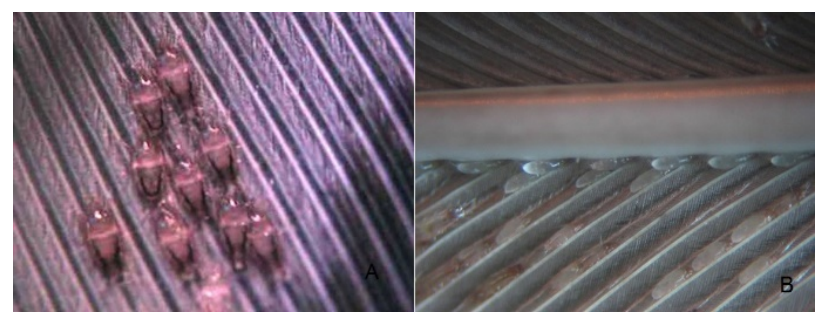

Şekil 7. A- Örtü teleklerindeki Trouessartia cinsine ait ergin bireyler, B- Uçma teleklerindeki Proctophyllodes cinsine ait ergin ve nimfler.

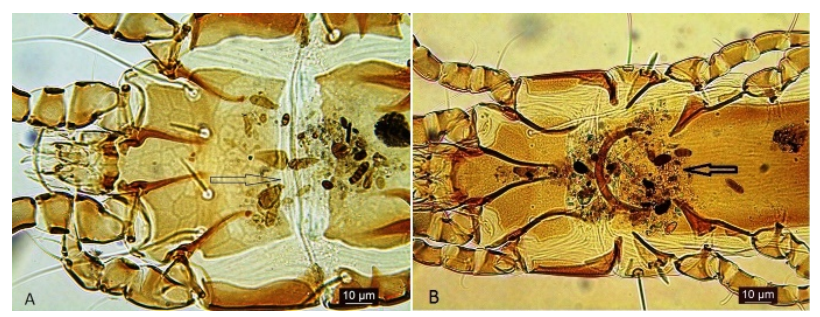

Şekil 8. A- Trouessartia sp. (dişi), B- Proctophyllodes sp. (erkek), bireyin besin içeriği.

Bir araştırmada tüylerin yapısal çeşitliliği, farklı yöntemler kullanılmasına rağmen aynı ya da benzer akar türlerinin tespit edilmesinde ve tespit edilen toplam akar türü sayısında önemli rol oynamaktadır (Proctor \& Owens, 2000). Bu araştırmada her ilkbaharda 7 akar türü tespit edilmiştir. Sonbaharda bu rakam tüy toplama yönteminde 9 piretrin ve pens kullanımında 10'a ulaşmıştır. Piretrin kullanıldığında vücuttaki tüm ektoparazitler tespit edilmekte ancak bu akarların mikrohabitatları tespit edilememektedir. Pens kullanıldığında vücut yüzeyindeki her bölge incelenip tüm mikrohabitatlara ulaşılmaktadır. Tüy toplandığında ise tüyün yapısal çeşitliliğine bağlı olarak belirli bir mikrohabitat incelenebilmektedir. Piretrin tozu kullanıldığında bazı taneciklerinin tüylerin arasında kalabildiği gözlenmiştir, göçe devam edecek bu kuşların daha az etkilendiği tespit edilmiştir. Pens ile akar toplama yönteminde hem mikrohabitatların hepsine ulaşılabilmekte hem de konak kuş daha az stres altında kalmaktadır. Ancak bu metotta kuşu uzun süre stereo mikroskop altında incelemek gerekebilmektedir. Bu nedenle stres faktörü göz önüne alınarak hızlı bir şekilde kısa bir zaman aralığında inceleme tamamlanmalıdır. Ayrıca araştırmacının bu konuda deneyimi arttıkça daha hızlı inceleme yapabilmektedir.
Kuş ektoparazitlerinin incelenmesinde kuyruk ya da uçma teleklerinin yoğun ışığa maruz birakılması, kullanılabilir bir yöntem olsa da Tüy Akarları (Astigmata) kitabının yazarı Heather Proctor'un kişisel gözlemlerine göre sinırlı bir bölgede hareket eden tüy akarları 1şıktan çok etkilenmeyen, küçük boyutlu, açık renkli ve yavaş hareket eden canlılar oldukları için bu yöntem hatalı sonuçlar verebilmektedir. İncelemede büyüteç ya da diseksiyon mikroskobu kullanılması daha hassas sonuçlar vermektedir. Bu çalışmada diseksiyon mikroskobu kullanılarak akar toplanırken cins düzeyinde sınıflandırma yapılabilmiştir. Bu durum arazi çalışması sırasında hangi akar cinslerinin konak kuşun hangi vücut bölgelerinde yoğunlaştığını da göstermiştir.

Başka ülkelerde farklı tüy akarı toplama yöntemleri aynı çalışma içerisinde karşılaştırılmamış olup bu araştırmalarında müze örnekleri, pens ile canlı birey üzerinden toplama ve ölü hayvan üzerinden toplama yöntemi yaygın olarak kullanılmıştır (Berthold, 1990; Kolarova \& Mitov., 2008; Mironov, 1996; 1997; Shoker, Tawfek, Ibrahim, \& Osman, 2001; Rubtsov \& Yakimenko, 2012).

Canlı kuşların üzerindeki parazitler küçük ve hareketli oldukları için tüyler arasında onları bulabilmek bazen çok zor olmaktadır. Pratikte bir kuş bir ya da daha fazla ektoparazit grubunu barındırabilmektedir. Farklı ektoparazitler konağın farklı bölgelerine yerleşmiş olabileceği için detaylı inceleme önemlidir (Peters, 1933). Kızılırmak Deltası'nda yakalanan kuşlar arasında bit enfestasyonu Alcedo atthis (Yalıçapkını), Merops apiaster (Arıkuşu), Accipiter nisus (Atmaca) ve Upupa epops (İbibik) türlerinde yüksektir (Dik, Erciyas-Yavuz, Per, 2017). Kuşlar çok çeşitli ektoparazit (bit, pire, sinek, akar, kene) için bir liman gibidir. Ancak bu çalışmada pestisit de dâhil farklı örnek toplama yöntemleri kullanılmış olmasına rağmen sadece akar türleri tespit edilmiştir, diğer ektoparazitlere rastlanmamıştır.

Genellikle kuşlar ilkbaharda göç öncesinde tüylerini değiştirmektedir. Buna bağlı olarak akarların popülasyonu yaz sonunda artmaktadır (Mcclure, 1989). Bu çalışmanın sonucunda Passeriformes takımına ait türlerin tüy akarlarının belirlenmesinde stereomikroskop kullanılarak pens ile akarların toplanması yöntemi ile bir yıllık alan çalışmasının temel bir araştırma için yeterli olduğu tespit edilmiştir. Her ilkbaharda 7 sonbaharda 9-10 akar türü tespit edilmiştir. Acrocephalidae, Phylloscopidae, Scotocercidae ve Sylviidae familyasına ait türlerde yapılan akar incelemesinin yıllara ve mevsimlere göre dağılımına bakıldığında özellikle sonbahar döneminde incelenen kuş birey sayısındaki artış üreme dönemi sonrası tüy değişimi, popülasyon artışı ve halkalama istasyonunun Karadeniz'in kiyısında olmasından kaynaklanmış olabilir. Bu çalışmada sonbahar döneminde ilkbahar dönemine oranla ortalama üç kat daha fazla kuş bireyi yakalanmıştır. Araştırmaya konu olan familyalara ait türlerin ilkbahar ve sonbahar göçü geniş bir zaman diliminde cephesel olarak gerçekleşmektedir. Sonbaharda Afrika'dan yorgun gelen bireyler ile ilkbaharda Avrupa'ya gidecek bireyler bu bölgede beslenmekte ve göçe hazırlanmaktadır.

Tarihsel olarak tüy akarlarının konak-parazit özelleşmesinin uyumu incelendiğinde biyolojik, ekolojik ve zoocoğrafik veriler gerekmektedir. Bu nedenle akarın coğrafi dağılımı ile kuş üzerindeki mikro dağılımı da 
önemlidir. Burada kuşun yuvalama davranışı, toz banyosu yapması, sürü oluşturması, uçuş tüylerinin özellikleri dikkate alınmalıdır (Peterson, 1975). Araştırma konusu olan Acrocephalidae, Phylloscopidae, Scotocercidae ve Sylviidae türleri benzer yuvalama davranışı gösteren, sadece göç döneminde sürü oluşturan ve toz banyosu yapmayan türlerdir.

Bazı akarlar konağın; tüy, ölü deri, vücut sıvısı ve dokusundan beslenmektedir. Farklı kuş türü ve bireyleri farklı derecelerde parazitlenebilir. Bir bireyin tüm vücudunda bulunabilirken başka bir bireyde bulunmayabilmektedir (Watson \& Amerson, 1967). Analges ve Proctophyllodes cinsine ait türler kanat tüylerinin yanı sıra göğüs ve sırt tüylerinde de bulunmaktadır (Peters, 1933). Bu araştırmada kuyruk ve uçma teleklerinde Proctophyllodes, karın tüylerinde ise Analges cinsi tüy akarlarının yaşadığı tespit edilmiştir.

Tüy akarları; kuşların derilerinde ve tüylerinde sürekli parazit ya da simbiyont olarak yaşayan astigmatid akarların geniş bir grubudur (Peterson, 1975; O'Connor, 1982a; 1982b; Gaud \& Atyeo, 1996; Mironov, 1999; Dabert \& Mironov, 1999; Proctor \& Owens, 2000; Proctor, 2003). $\mathrm{Bu}$ görüşün aksini savunan çalışmalar da mevcuttur. Bu canlıların konakları ile olan etkileşimlerinin niteliği (kommensalizm, mutualizm veya parazitizm), hala belirsizliğini korumaktadır. Ancak tüy akarları ile ilgili çalışmalar kuş akar etkileşiminin muhtemelen parazitlikten mutualizme doğru gittiğini göstermektedir (Walter \& Proctor, 1999; Proctor \& Owens, 2000; Blanco, Tella, Potti, \& Baz, 2001). Geçmişte pek çok araştırmacı, tüy akarlarını kuşlara zarar veren bir ektoparazit olarak değerlendirmiştir. Ancak günümüzde tüy akarları, kuşlarda en sık görülen ektosimbiyontlardır.

Cernek Kuş Halkalama İstasyonu'nda yakalanan Acrocephalidae, Phylloscopidae, Scotocercidae ve Sylviidae familyasına ait bazı ötücü türleri arasında en yüksek enfestasyon oranı Sylvia atricapilla (\%94.8) ve Sylvia borin (\%74.5)'de tespit edilmiştir. Sylviia melanocephala (\%23.3) ve Sylvia curruca (\%19.4) ise enfestasyon oranı en düşük olan türlerdir (Per \& Aktaş, 2018). Bazı ötücü türleri üzerinde yapılan incelemelerde genellikle bireylerin uçuş ve kuyruk teleklerinde yoğun bir tüy akarı enfestasyonu tespit edilmiştir. Buna rağmen tüy akarlarından dolayı zarar görmüş bitkin ve sağlıksız bir kuş bireyi gözlenmemiştir. Halkalama istasyonunda farklı yıllarda kuş halka numaralarından yapılan kontrollerde aynı bireyler yeniden yakalanmış ve tüylerin üzerinde tekrar tekrar aynı akar türleri tespit edilmiştir. Bu durum kommensalizm görüşünü desteklemektedir. Bu çalışma için bazı Passeriformes türlerinin seçilme nedeni, genellikle bu türlere ait her bir bireyin yoğun tüy akarı enfestasyonuna maruz kalmasıdır. Eğer tüy akarları ektoparazit özelliği gösteren canlılar olsaydı bir kuş bireyinin tüylerini yoğun bir şekilde işgal etmişken, bu bireyin sağlıklı kalması, tüylerinin dökülmemesi, tüylerin yapısının bozulmaması ve tekrar tekrar göç edebilmesi mümkün olamazdı.

Tüy akarları, konağın tüylerindeki mantarları yiyerek konağa yarar sağlamaktadır (Blanco et al., 2001). Çoğu tüy akarının yağ salgısı ile beslendiği bilinmektedir, bu canlılar aynı zamanda mantar sporları ve bu salgı içindeki diğer maddeler ile de beslenmektedir ( $\mathrm{O}^{\prime}$ Connor, 1982a; 1982b). Bu çalışma için hazırlanmış olan preparatlarda birçok bireyde sindirilmemiş besin içerikleri görüntülenebilmiştir, bu görüntülerdeki besinlerin mantar olduğu düşünülmektedir (Şekil 8).

$\mathrm{Bu}$ araştırmada Acrocephalidae, Phylloscopidae, Scotocercidae ve Sylviidae familyasına ait kuş türlerinde farkl1 mikrohabitatlarda; Analges, Dolichodectes, Proctophyllodes, Strelkoviacarus ve Trouessartia cinsine ait toplam 10 akar türü tespit edilmiştir. Üç farklı örnek toplama yöntemi karşılaştırıldığında; tür çeşitliliği, çalışma kolaylığı, süre, etik ve farklı habitatlara özgü akar türlerinin tespit edilmesi açısından stereo mikroskop kullanılarak pens ile akar toplamanin en uygun yöntem olduğu düşünülmektedir. Halkalama istasyonunda benzer bir araştırma için tüy akarlarının belirlenmesi amacıyla stereo mikroskop ve pens kullanılarak bir yıllık alan çalışması yapılması yeterli olacaktır. Kuşların göç yollarının araştırıldığı bir halkalama istasyonunda yapılmış olan bu araştırma, Türkiye'de gelecekte yapılması planlanan taksonomi temelli akaroloji araştırmalarının disiplinler arası bir yaklaşım ile farklı ilgi alanlarından uzmanlar ile planlanması gerektiğini göstermektedir. Halkalama istasyonları, kuşlara zarar vermeden, konak ve parazit temelli izleme çalışmaları yapılabilmesine imkân vermektedir.

Teşekkür: Bu araştırmanın arazi çalışmaları Tarım ve Orman Bakanlığı, Doğa Koruma ve Milli Parklar Genel Müdürlüğü'nün izni ile Samsun Ondokuz Mayıs Üniversitesi Ornitoloji Merkezi'nden Yakup Sancar Barış, Kiraz Erciyas-Yavuz, Nizamettin Yavuz, Arif Cemal Özsemir ve Arzu Gürsoy Ergen'in katkıları ile gerçekleştirilmiştir. Verilerin değerlendirilmesinde Heather Proctor ve Sergey Mironov tüy akarları ile ilgili kaynakları, bilgi ve gözlemlerini paylaşarak, Zafer Karaer, Abdullah Hasbenli ve Selami Candan ise bilimsel önerileri ile katkı sağlamıştır. Bu araştırma 22. Ulusal Biyoloji Kongresi, 23-27 Temmuz 2014, Osmangazi Üniversitesi, Eskişehir, Türkiye'de sunulmuş ve çalışmanın özeti yayımlanmıştır.

\section{Kaynaklar}

Aksın, N. (2007). Freyana anatina (Koch, 1844) feather mites (Acarina, Freyanoidea) recorded for the first time on wild ducks (Subfamily, Anatinae) in Turkey. Acta parasitologica Turcica, 31, 302-305.

Aksın, N. (2010). Chewing lice and feather mites on wild partridges. Indian Veterinary Journal, 87, 940-941.

Aksın, N. (2011). Feather mites (Acari: Astigmata) on wild quail (Coturnix coturnix). Indian Veterinary Journal, 88, 69-70.

Aksın, N., \& Erdoğmus, Z. (2005). Pseudolichus solutocurtus Dubinin, 1956 (Acarina, Pterolichoidea) and Harpirhynchus sp. (Acarina, Harpirhynchidae Dubinin, 1957) species recorded for the first time on wild partridges in Turkey. Turkish Journal of Veterinary and Animal Sciences, 29(11), 49-56.

Atyeo, W.T., Braasch N.L. (1966). The feather mite genus Proctophyllodes (Sarcoptiformes: Proctophyllodidae), Bulletin of the University of Nebraska State Museum, 5, 1-354.

Berthold, P. (1990). Spatiotemporal programs and genetics of orientation. Experientia, 46, 363-371.

Blanco, G., Tella, J.L., Potti, J., \& Baz, A. (2001). Feather mites on birds: costs of parasitism orconditional outcomes? Journal of Avian Biology, 32(3), 271-274.

Clayton, D.H., \& Walther, B.A. (1997). Collection and quantification of arthropod parasites of birds, Clayton D.H., Moore J., (eds.) Host-Parasite Evolution: General Principles and Avian Models (pp. 419-440). England, Oxford University Press., 488 pp.

Dabert, J., \& Mironov, S.V. (1999). Origin and evolution of feather mites (Astigmata). Experimental and Applied Acarology, 23, 437-454.

Dik, B., Erciyas-Yavuz, K., \& Per, E. (2017). Chewing lice (Phthiraptera: Amblycera, Ischnocera) on birds in the Kizılırmak delta, Turkey. Revue de Médecine Vétérinaire, 168(1-3), 53-62.

Doğa Koruma ve Milli Parklar Genel Müdürlüğü, (2018). Türkiye Ulusal Halkalama Çalışmaları Raporu, Tarım ve Orman Bakanlığı, Ankara.

Dubinin, V.B. (1951). Feather mites (Analgesoidea). Part I. Introduction to the study, Fauna U.S.S.R. Arachnida, 6, 1-363. 
Gaud, J., \& Atyeo, W. T. (1996). Feather mites of the World (Acarina, Astigmata): the supraspecific taxa. Annales du Musée Royal de l'Afrique Centrale, Sciences Zoologiques, 277, 1-193.

Gürler, A.T., Mironov, S.V., \& Erciyas-Yavuz, K. (2013). Avian feather mites (Acari: Astigmata) of Samsun, Turkey. Acarologia, 53(1), 17-23.

Kolarova, N.T. \& Mitov, P.G. (2008). Feather mites of the Superfamily Analgoidea (Acari: Astigmata) from Passerines (Aves: Passeriformes) in South Dobrudzha, Bulgaria. Acta Zoologica Bulgarica, Suppl. 2, 93-104.

McClure, H.E. (1989). Occurrence of feather mites (Proctophyllodidae) among birds of Ventura county lowlands. California, Journal of Field Ornithology, 60(4), 431-450.

Mironov, S.V., \& Fain, A. (2003). New species of the feather mite subfamily Pterodectinae (Astigmata: Proctophyllodidae) from African passerines (Aves: Passeriformes). Bulletin de la Societé Royale Belge d'Entomologie, $139,75-91$

Mironov, S.V., \& Galloway, T.D. (2002). New feather mite taxa (Acari: Analgoidea) and mites collected from native and introduced birds of New Zealand. Acarologia, 42, 185-201.

Mironov, S.V. (1996). Feather mites from passerines of the north-west of Russia. Parasitologiya, 30, 521-539.

Mironov, S.V. (1999). Feather mites: general morphological adaptations, phylogeny and coevolutionary relationships with birds. Ekologija, 2, 5766.

O'Connor, B.M., (2009). Cohort Astigmatina, In: Krantz G.W., \& Walter D.E. (Eds.). A Manual of Acarology (pp. 565-657) USA, Texas, Texas Tech. University Press., 816 pp.

O'Connor, B.M. (1982a). Evolutionary ecology of astigmatid mites. Annual Review of Entomology, 27, 385-409.

O'Connor, B.M. (1982b). Acari: Astigmata, In: Parker S.P (Ed.). Synopsis and classification of living organisms (146-169). USA, New York, McGraw-Hill Press., 1119 pp.

Park C.K., Atyeo, W.T. (1971). A generic revision of the Pterodectinae, a new subfamily of feather mites (Sarcoptiformes: Analgoidea), Bulletin of the University of Nebraska State Museum, 9, 39-88

Per, E., \& Aktaş, M. (2018). The Monitoring of Feather mites (Acari, Astigmata) of the Warbler (Aves: Sylviidae) Species in the Kızılırmak Delta, Samsun, Turkey. Turkish Journal of Zoology, 42, 394-401.

Perez, T.M., \& Atyeo, W.T. (1984). Site selection of feather and quill mites of Mexican parrots. In: Acarology (pp.563-570). Griffiths, D.A., \& Bowman C.E. (Eds.). England, Chichester, VI. Ellis Horwood Ltd.

Peters, H.S. (1933). External parasites collected from banded birds. BirdBanding, 4, 68-75.

Peterson, P.C. (1975). An analysis of host-parasite associations among feather mites (Acari: Analgoidea). Miscellaneous Publications of the Entomlogical Society of America, 9, 237-242.

Proctor, H., \& Owens, I. (2000). Mites and birds: diversity, parasitism and coevolution. Tree, 15(9), 358-364.

Proctor, H.C. (2003). Feather Mites (Acari: Astigmata): Ecology, Behavior, and Evolution. Annual Review of Entomology, 48, 185-209.

Rubtsov, G.A., \& Yakimenko, V.V. (2012). The feather mite (Astigmata) fauna of some passerine birds (Passeriformes) in the South of. Western Siberia. Entomological Review, 92(9), 1020-1031.

Santana, F.J. (1976). A review of the genus Trouessartia, Journal of Medical Entomology Suppl., 1, 1-128

Shoker, N.I., Tawfek, N.S., Ibrahim, M.H., \& Osman, E.S. (2001). Mites associated with some birds in El-Minia governorate, upper Egypt. Egyptian Journal of Biology, 3, 124-136.

Walter, D.E., \& Proctor, H.C. (1999). Mites: Ecology, Evolution and Behaviour. CABI Publishing, 352pp.

Watson, G.E., \& Amerson, A.B. (1967). Instructions for Collecting Bird Parasites. Smithsonian Institution Information, 477, 1-12. 